\title{
Discursos no feminino na imprensa pedagógica de inspiração católica: Página de Castelo Branco e Seiva - Revista de Cultura (1953-1959)
}

\author{
Women's speeches in the Catholic-Inspired \\ Pedagogical Press: "Página de Castelo Branco" and \\ "Seiva - Revista de Cultura" (1953-1959) \\ Discursos femeninos en la prensa pedagógica de \\ inspiración católica: "Página de Castelo Branco" y \\ “Seiva - Revista de Cultura” (1953-1959)
}

HÉLDER HENRIQUES (iDa JUSSARA SANTOS PIMENTA

\section{Resumo}

O artigo propõe uma análise dos discursos femininos, sobretudo de alunas normalistas, publicados em dois periódicos, de inspiração Católica, da Escola Particular do Magistério Primário de Castelo Branco (Portugal) na década de 50 do século XX. Pretendemos evidenciar o modo como as autoras foram incorporando e produzindo a sua identidade num contexto formativo, social e político enquadrado por uma forte moral cristã. Procuramos identificar, discutir e interpretar os discursos produzidos por alunas e/ou professoras através da Página de Castelo Branco (1953-1954) e da Seiva - Revista de Cultura (1955-1959). Através de uma abordagem metodológica assente na crítica

\footnotetext{
${ }^{a}$ Instituto Politécnico de Portalegre (IPP), Portalegre, Portugal. Investigador integrado do Centro de Estudos Interdisciplinares do Século XX, da Universidade de Coimbra - Ceis20 - GRUPOEDE (Portugal). Doutor em Ciências da Educação, e-mail: helderhenriques@esep.pt

b Universidade Federal de Rondônia (UNIR), Porto Velho, RO, Brasil. Doutora em Educação, e-mail: jussara.pimenta@unir.br
} 
histórica, defendemos a possibilidade da emergência de duas configurações identitárias associadas às autoras: uma identidade atribuída e uma identidade adaptada.

Palavras-chave: Identidade. Formação. Estado Novo. Portugal.

\begin{abstract}
The article proposes an analysis of the feminine discourses, especially magisterium students, published in two periodicals, of Catholic inspiration, in the Particular School of Primary Magisterium of Castelo Branco (Portugal), in the decade of 50 of century XX. We intend to show how the authors were incorporating and producing their identity in a formative, social and political context framed by a strong Christian morality. We sought to identify, discuss and interpret the discourses produced by students and / or teachers through the "Página de Castelo Branco" (1953-1954) and the "Seiva - Revista de Cultura" (1955-1959). Through a methodological approach based on historical criticism, we defend the possibility of the emergence of two identity configurations: an attributed identity and an adapted identity.
\end{abstract}

Keywords: Identity. Formation. Estado Novo. Portugal.

\title{
Resumen
}

El artículo presenta un análisis de los discursos femeninos, especialmente de estudiantes normalistas, publicado en dos revistas de inspiración católica de la Escuela Privada de Magisterio Primario de Castelo Branco (Portugal), en los años 50 del siglo XX. Tenemos la intención de mostrar cómo las autoras fueron incorporando y produciendo su identidad en un contexto formativo, social y político enmarcada por una fuerte moral cristiana. Buscamos identificar, analizar e interpretar los discursos producidos por las estudiantes y / o profesoras a través de la "Página de Castelo Branco" (1953-1954) y "Seiva - Revista de Cultura" (1955-1959). A través de un enfoque metodológico basado en la crítica histórica, defendemos la posibilidad de lo surgimiento de dos configuraciones de identidad asociados a las autoras: una identidad atribuida y una identidad adaptada.

Palabras clave: Identidad. Formación. Estado Novo. Portugal.

\section{Introdução}

O presente artigo assume o propósito de analisar os discursos femininos publicados na imprensa pedagógica produzida no interior de uma escola particular de formação de professores em Portugal, de inspiração católica, na década de 50 do século XX. Para responder a este objetivo formulamos um conjunto de questões orientadoras: Que tipo de configurações identitárias as autoras (alunas e/ou professoras) foram produzindo ou incorporando através da imprensa pedagógica 
específica daquela instituição? Quais os principais assuntos que abordavam? Quem eram essas autoras (alunas e professoras)?

De forma a tentarmos responder a estas questões/inquietações científicas convocamos autores diversos (NÓVOA, 1992; 1993; HENRIQUES, 2011; 2012; PIMENTEL, 2001; CHARTIER, 2002; HERNANDEZ DIAZ, 2015; CATANI, 1999; ESCOBAR, 2004; ARAÚJO, 1990; BERGER; LUCKMANN, 2004; FISCHER, 2001; entre outros ) que permitiram ir ao encontro de três conceitos específicos de análise - Formação; Identidade; Género - que, por sua vez, possibilitaram ampliar o nosso olhar sobre o assunto em questão. O corpus documental é constituído por dois núcleos de fontes de informação: fontes de arquivo (nomeadamente, Livros de Exames de Estado) e imprensa pedagógica. Neste ponto, em particular, utilizamos os periódicos da Escola Particular do Magistério Primário de Castelo Branco Página de Castelo Branco e Seiva - Revista de Cultura. Reconhecemos, seguindo de perto os trabalhos desenvolvidos por Nóvoa (1993), Catani e Sousa (1999) ou Hernandez Diaz (2015), que a imprensa pedagógica apresenta múltiplas vantagens enquanto fonte de informação. A este propósito, Hernandez Diaz (2015) é perentório quando afirma que:

La prensa pedagógica, desde su própria identidad, se convierte en un objecto historiográfico específico, com un valor añadido, en la medida que se erige en un canal informativo de los problemas educativos del tiempo histórico en que desempeña su actividad. Por otra parte, la prensa pedagógica representa una forma posible de aproximación al conocimiento del sistema educativo [...] diferente a las clássicas formas de conocimiento histórico, porque la prensa pedagógica incluye el mismo tiempo una lectura transversal del problema educativo que se aborda, que combina la dimensión normativa, con la denuncia, con la difusión de nuevas ideas y pautas pedagógicas (p. 10).

A análise metodológica realizada rege-se pela crítica histórica uma vez que desse modo podemos triangular as fontes, colocá-las em “crise” e validá-las interna e externamente. Neste texto, defenderemos que as autoras analisadas se apropriaram de uma identidade que lhes foi atribuída, embora, por outro lado, procuraram adaptarse às circunstâncias especificas do contexto sociopolítico e, na medida do possível, afirmar a sua condição de mulheres e alunas/professoras. 


\section{Formação, Identidade e Discursos}

A partir da década de 80 do século XX, a temática das identidades ganhou fôlego no âmbito da investigação em Ciências Sociais e Humanas. Construíram-se diferentes problemáticas relacionadas, entre outros, com as histórias de vida, as relações entre diferentes atores, a socialização dos indivíduos ou as questões relacionadas com a mobilidade social e/ou profissional. Acresceram a estas problemáticas um conjunto de variáveis - como o género - que permitiram aumentar, ainda mais, o já amplo campo de ação das "identidades". Entendemos que a identidade "é o resultado simultaneamente estável e provisório, individual e colectivo, subjectivo e objectivo, biográfico e estrutural, dos diversos processos de socialização que, em conjunto constroem os indivíduos e definem as instituições" (DUBAR, 1997, p. 105). Assumimos que este é um conceito plural e dinâmico que nos remete para o domínio do simbólico e das interações entre os indivíduos. De acordo com Pinto (1991), a produção das identidades acontece por referência a uma dinâmica permanente entre a unidade e a diferenciação. Como afirma Tavares (2007), apoiado em Dubar (1997), as identidades:

[...] são construídas socialmente enquanto produtos de sucessivos processos de socialização em que os indivíduos aprendem as normas, os papéis e as práticas sociais através da interiorização de valores, no quadro de uma construção lenta e gradual de um código simbólico assente num conjunto de representações sociais (p. 31).

Na verdade, colocar em diálogo os indivíduos, em contexto de grupo, através da categoria social de género constitui uma abertura na visão sobre a produção de identidades, na medida em que não estamos a falar apenas da formação escolar, mas também das representações sociais e de poder sobre os indivíduos. É neste sentido que Escobar (2004) afirma o seguinte:

[...] o conceito de identidade como tem sido estudado é para nós insuficiente, porque não integra a análise da articulação entre identidade socioprofissional e a identidade de género, questão fundamental [...]. A forma como têm abordado a identidade deixa escondidas as relações e poderes de género que são relações desiguais na nossa sociedade. A desigualdade de género [...] atravessa toda a sociedade, percecionada como uma sociedade patriarcal. Numa sociedade assim desigual, onde aos homens e às mulheres, enquanto grupos sociais, são atribuídos papéis, estatutos e poderes diferentes, necessariamente as profissões serão genderizadas (p. 23). 
As atividades "genderizadas" remetem-nos para um campo de poderes, de lutas e tensões de que é exemplo o grupo das professoras de ensino primário em Portugal. É diferente compreender o modo como se foram produzindo as identidades socioprofissionais dos indivíduos e/ou grupos se tivermos em conta a categoria de género. Entendemos este conceito como uma categoria social que influência as escolhas profissionais. O caso da profissão de professor é paradigmático do que acabamos de referir. A maioria do grupo socioprofissional dos professores é constituído por elementos do género feminino. Parece haver uma perspetiva de continuidade de um conjunto de atividades de natureza privada associadas às mulheres que ao abraçarem a profissão de professora encontraram uma forma de mobilidade aceite pela sociedade dado que constitui um prolongamento daquilo que o universo social espera delas no domínio do privado.

A compreensão das questões identitárias implica a seleção de um objeto de estudo definido que permita evidenciar relações de poder existentes numa determinada época. É neste contexto que é relevante compreender o conceito de “discurso". De acordo com Fischer (2001), o discurso ou enunciado permite que "nos defrontemos com a nossa história ou nosso passado aceitando pensar de outra forma o agora [...]” (p. 222). Efetivamente, a análise realizada a partir dos discursos permite estabelecer uma ponte entre o presente, dado como adquirido e não questionado, e um passado silencioso que permite colocar em "crise" o presente do indivíduo e/ou grupo.

A análise dos discursos remete-nos para um campo de poder. Um campo discursivo dinâmico, que não descreve apenas os objetos mas que, ele próprio enquanto discurso, é um ator central da investigação dado que os discursos estão associados a práticas, comportamentos, hábitos, atitudes e pensamentos que existem num determinado tempo e espaço, devendo ser considerados, por isso, como verdadeiros “acontecimentos” (Fischer, 2001, p. 202). É neste sentido que a autora que temos acompanhado se refere aos discursos relacionados com os estudos sobre a mulher quando afirma que "[...] seus enunciados têm força de "conjunto" e se situam como novos campos de saber [...]” (FISCHER, 2001, p. 203). 
Quando falamos de discursos ou de formações discursivas entendemos que estamos a pensar num campo de tensões, de lutas e de poderes. Como refere Fischer (2001) um campo "inteiramente vivo [...]. Tudo nele se cruza, estabelece relações, promove interdependências. O que é dissonante também é produtivo, o que semeia a dúvida é também positividade crítica” (p. 210). Recuperamos, para clarificar, o pensamento de Fischer (2001) com:

[...] o exemplo da "jovem mulher de 40": esse discurso não será analisado bem como "expressão de uma conjuntura", nem idealmente como mera criação simbólica. Associada a uma série de conquistas sociais, essa proliferação de textos sobre a mulher - convidada a ultrapassar a antiga posição romântica, a falar de seus desejos sexuais e seu prazer e a buscar uma maturidade cheia de beleza e atrativos - deve ser analisada a partir das práticas a que esse discurso está associado. Tais práticas, por sua vez, expõem uma série de lutas, a começar pela luta básica relativa ao confronto de homens e mulheres e se tornam visíveis na superfície dos corpos femininos. Sabendo-se que vários campos, como o da moda, da medicina estética, ginecológica e endocrinológica, e da psicologia, entre outros, disputam a hegemonia de uma discursividade sobre essa mulher, trata-se de desenhar as margens dos enunciados aí produzidos e fazer aparecerem as diferenças, as congruências e as comunicações, ocupando-se principalmente em descrever as práticas efetivas a que eles fazem referência - práticas que conformam cotidianos, definem projetos de vida, moldam, transformam e desenham os corpos. Se a mulher fala e é falada [...] ela de algum modo se confronta com o poder (p. 218-219).

Para ir ao encontro destas formações discursivas relacionadas com o universo educacional feminino percebemos que a base deste trabalho poderia ser uma escola normal de formação de professores. Nessa instituição procuramos fontes que permitissem identificar, categorizar e analisar os discursos, principalmente, de alunas normalistas e professoras que estavam associadas a esse universo particular. Neste sentido, a escolha recaiu sobre uma instituição de formação de professores situada no interior de Portugal - numa cidade chamada Castelo Branco - que impulsionou duas publicações periódicas, nos anos 50 do século XX, onde as alunas e as professoras podiam participar com os seus textos.

Além do que já referimos anteriormente, partimos do pressuposto que o início da definição da identidade socioprofissional do grupo das professoras do ensino primário encontra nos espaços formativos, em particular nas escolas de formação, um contexto ideal para se estruturarem princípios, comportamentos e/ou atitudes, assim como conhecimentos científicos, comuns que permitem a construção de uma ideia de pertença a um grupo. Como defende Nóvoa (1995), as escolas de formação de 
professores/as constituem espaços de socialização que permitem a apropriação de valores e de hábitos, assim como de conhecimentos de natureza científica, encontrando na formação escolar uma instância de socialização produtora de uma determinada identidade socioprofissional. Todavia, é importante não esquecer que a análise da produção das diferentes "formas identitárias" encontra-se dependente de um amplo conjunto de interações, também elas variáveis.

\section{A Mulher, o Catolicismo e o Estado Novo: um triângulo identitário}

E a mulher? Pergunto com certa curiosidade. Qual o papel que the destina nessa renovação de mentalidade? $E$ Salazar, vagamente mas elegantemente anti-feminista, como Mussolini, como quasi todos os ditadores: Deixemos [...] o homem a lutar com a vida no exterior, na rua...E a mulher a defendê-la, a trazê-la nos seus braços, no interior da casa...Não sei, afinal, qual dos dois terá o papel mais belo, mais alto e mais útil... (Entrevista de A. Ferro a $A$. Oliveira Salazar, 1933, p. 133).

O excerto anterior resultou de uma entrevista realizada por António Ferro (do Secretariado de Propaganda Nacional) a António de Oliveira Salazar no começo da década de 30 do século XX. A resposta dada à pergunta do jornalista evidencia bem o papel que o mentor do Estado Novo português reservava para a mulher. Este papel era essencialmente moral e de natureza privada. Esta condição moralizante e privada atribuída pelo regime político face ao papel da mulher não impediu, porém, que esta exercesse algumas atividades ocupacionais ou profissionais na esfera pública. É o caso, entre outros, das enfermeiras (HENRIQUES, 2012; ESCOBAR, 2004; FERREIRA, 2013) e das professoras para o ensino primário (ARAÚJO, 1990). Estas atividades desenvolvidas maioritariamente por mulheres no interior do regime político do Estado Novo constituem, em abono da verdade, uma forma de mobilidade social, mas também um mecanismo de controlo desse processo pelo Estado em articulação com a Igreja. Isto é, se por um lado o Estado permitiu o exercício de atividades públicas às mulheres, por outro lado encontrava-se bem definido que tipo de atividades podiam desenvolver. Essas atividades, em regra, constituíam um prolongamento da maternidade e da arte de educar no espaço privado ampliado para o cuidar e ensinar à sociedade em geral, colocando-se ao serviço do 
próximo. A este propósito Araújo (1990), num trabalho já clássico, afirma a propósito da condição da mulher no Estado Novo em Portugal:

As mulheres eram, pois, construídas ideologicamente como aquelas cujas atividades se esgotavam na esfera doméstica, em torno do cuidado dos filhos, da casa e do marido, pela qual era responsabilizada, mas numa situação de subordinação em relação aos elementos masculinos. E, no entanto, a retórica salazarista apresentava a família como a célula central [...] (p. 88).

Não fugiu a esta condição a atividade de professora do ensino primário na medida em que representava, de algum modo, o projeto Salazarista para a sociedade portuguesa. Todo este processo encontrava-se envolvido por uma intensa moral cristã que constituía fundamento de toda a atividade feminina no espaço público. Os ideais cristãos estavam bem presentes no contexto do exercício da atividade de professora uma vez que estas mulheres que procuravam um trabalho assalariado, e, portanto, alguma autonomia, continuavam a representar os ideais de sacrifício, abnegação, de bondade e entrega ao sacerdócio que deveria ser o exercício do magistério primário.

A partir de meados da década de 30 da centúria passada, depois de publicado o Estatuto da Ação Católica Portuguesa, a Igreja organizou-se e procurou fundar instituições vocacionadas para moldar a juventude feminina. Entre elas destacaram-se duas: a Liga de Acção Católica Feminina e a Juventude Católica Feminina. Como afirma Pimentel (2001) estas instituições de inspiração Católica permitiram uma definição mais concreta sobre o que seria o papel da mulher, a partir da década de 30 do século XX, nomeadamente "a manutenção do lar e a educação dos filhos no espaço privado, a assistência e a educação no espaço público foram as tarefas atribuídas às mulheres pelas associações femininas filantrópicas e beneficentes, na sua maioria dependentes da Igreja" (p. 109). O Estado Novo soube interpretar o papel que essas organizações de inspiração Católica podiam ter na sociedade e aproveitou o seu potencial.

$\mathrm{Na}$ década de 40, do século XX, assistimos a um reforço da influência da Igreja no contexto do Estado Novo, tornando o/a professor/a de ensino primário/a um/a promotor/a da nação e da moral cristã. Este reforço aconteceu na sequência da assinatura da Concordata, em 1940, com a Santa Sé. Reservava-se à Igreja o "livre exercício da sua autoridade" com particular incidência nas instituições escolares. É 
precisamente neste sentido que Nóvoa (1992) afirma a importância da criação da disciplina de Religião e Moral e a sua institucionalização, a partir de 1947, sob a orientação da própria Igreja (p. 511) no processo de difusão de valores nacionalistas e católicos que alicerçaram o regime político.

Importa, no entanto, compreender especificamente que tipologias de discursos as mulheres e alunas normalistas ou professoras procuravam colocar em evidência. Este aspeto parece-nos relevante para compreender questões identitárias e discursivas ancoradas ao regime político do Estado Novo na década de 50 do século XX. Afinal, o que escreviam aquelas mulheres?

\section{A imprensa pedagógica na Escola Particular do Magistério Primário de Castelo Branco: Identificação}

A compreensão relacionada com as "formas identitárias" implica uma identificação e análise aos discursos produzidos pelas alunas e professoras num determinado período. Neste caso, olhamos com particular relevância para a década de 50 do século XX e para a publicação de dois periódicos que foram produzidos na Escola Particular do Magistério Primário de Castelo Branco.

Esta instituição foi fundada em 1951, por João Frade Correia, que sentiu a necessidade de desenvolver uma escola de formação de professores/as numa região do interior de Portugal onde não havia resposta pública. Esta escola funcionou até 1975, sempre liderada pelo seu fundador e diretor. O professor João Frade Correia nasceu a 17 de abril de 1913, numa pequena aldeia do concelho de Idanha a Nova Rosmaninhal (Portugal). A sua formação académica foi realizada entre Castelo Branco - onde concluiu os estudos secundários - e Coimbra - onde realizou os seus estudos superiores, em Ciências Histórico-geográficas, adquirindo o grau de licenciado em 1939 (HENRIQUES, 2012).

Foi um dinamizador no que se refere à criação de instituições direcionadas para o campo pedagógico. Promoveu a fundação das Salas de Estudo Luís de Camões; esteve na origem da Escola Comercial Pedro Nunes e fundou a Escola Particular do Magistério Primário Amato Lusitano/ Escola Particular do Magistério Primário de Castelo Branco onde desenvolveu o ideário católico no âmbito da formação de 
professores (HENRIQUES; ORLANDO, 2015). A este propósito é muito claro quando escreve sobre a missão que deveria ocupar o professor:

O professor deve ser, acima de tudo, um companheiro mais velho do aluno. A sua vida deve ser um exemplo vivo e penetrante na alma do educando. Se aquele não se impõe pelo exemplo, todas as suas palavras serão inúteis e vazias de sentido e sobretudo de vida [...]. Ensina-se rezando. Todas as lições do professor devem ser, acima de tudo, uma oração. Em todas as lições, as mais insignificantes, deve haver um vínculo que nos ligue a Deus. Quer se estudem as particularidades da terra, com todos os seus acidentes geográficos; das plantas, com toda a sua riqueza extraordinária e os mistérios da sua seiva; dos animais, com as suas vidas, as mais diversas...tudo isso forma esse livro grandioso, a natureza, que Deus fez expressamente para o homem aprender a viverem a elevar-se e a rezar. A Natureza, toda ela, é uma oração ordenada para Deus que o coração do homem deve rezar, numa comunhão efervescente; E quando a fé ilumina as almas toda a grandiosidade do universo cabe numa simples oração" (p. 3).

O texto mostra a importância da religião e da moral cristã, assumida por João Frade Correia, naquilo que deveria constituir o exercício do magistério do professor do ensino primário. Este conjunto de ideias foi replicado no âmbito da formação dos/as futuros/as professores/as tornando-se particularmente visível através da imprensa pedagógica associada à Escola do Magistério Primário de Castelo Branco.

Assim, verificamos a existência de uma folha semanal intitulada Página de Castelo Branco integrada no periódico de Coimbra "O Rumo”, com publicação entre 1953 e 1954; e, ainda, a publicação de uma revista intitulada Seiva - Revista de cultura, publicada entre 1955 e o final dessa década (1959) (embora tendo sido publicado um número único já na década de setenta). 
Figura 1 - A publicação Página de Castelo Branco (1953-1954)



Fonte: Biblioteca Municipal de Castelo Branco.

Figura 2 - Seiva - Revista de Cultura (1955-1959)

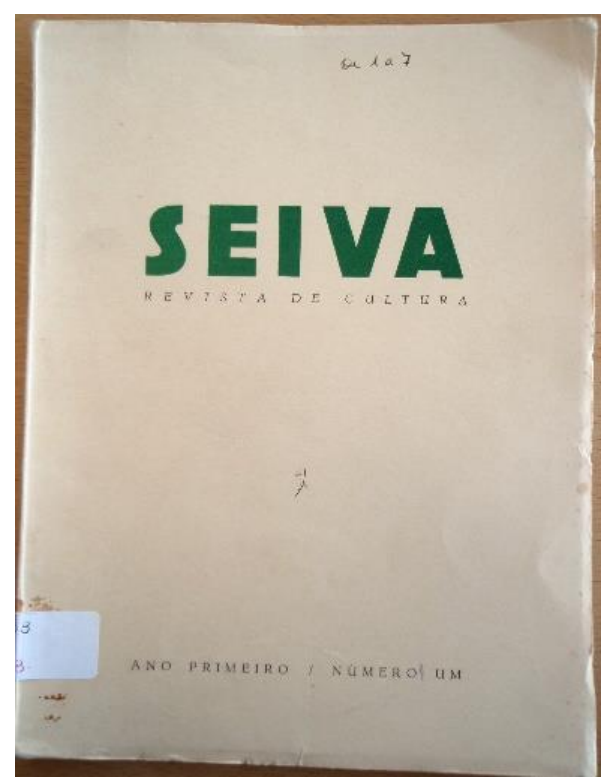

Fonte: Biblioteca Municipal de Castelo Branco. 
A Página de Castelo Branco foi o primeiro "periódico" da Escola Particular do Magistério Primário de Castelo Branco. A sua publicação, em Coimbra, prende-se com as relações de proximidade do diretor João Frade Correia com aquela cidade e, por outro lado, com o fato dos Exames de Estado serem realizados, naquela fase, na Escola do Magistério Primário de Coimbra, dada a sua natureza pública. Foram publicados 13 números. Os primeiros 8 números foram organizados pelas alunas normalistas Virgínia Pacheco Ramos Palma, Maria Manuela Feijão e Maria de Lourdes Correia. A partir do número 9 (15 de abril de 1954) a organização da folha foi assegurada pelas alunas Maria da Conceição Rego de Sousa e Maria Celeste Baltazar Dias. O propósito inicial desta folha semanal consistia no seguinte:

\begin{abstract}
As nossas primeiras palavras são para todos os que, unidos pelo mesmo ideal educativo, estão contribuindo para o alevantamento moral do povo português. São para Sua Ex. ${ }^{a}$ o Sr. Subsecretário da Educação Nacional, Sr. Dr. Henrique Veiga Macedo, que com o seu dinamismo, alto espirito patriótico e grande sacrifício, tudo tem feito para que todas as almas portuguesas sejam esclarecidas e incendiadas pela chama redentora das verdades cristãs. São ainda, as nossas primeiras palavras, para todos os diretores e professores das Escolas do Magistério, pois estão operando uma verdadeira transformação na juventude portuguesa: são também para todos os nossos colegas, mais velhos e mais novos, que estão formando e robustecendo os seus ideais no sincero desejo de que Portugal reencontre e cimente a certeza do seu destino, de molde a poder continuar no mesmo caminho de sempre (Página de Castelo Branco, n. 1, 1953)
\end{abstract}

A transformação da sociedade portuguesa de acordo com os princípios nacionalistas e cristãos assumiram-se como réplicas dos discursos orientadores do regime político no interior desta instituição escolar - de caráter particular - no âmbito da sua missão de formar futuros/as professores/as para o ensino primário.

Numa perspectiva pedagógica mais aprofundada, com artigos de maior alcance, embora ancorada nos mesmos princípios surgiu a Seiva - Revista de Cultura. Publicada entre 1955 e 1959, com periodicidade mensal, e dirigida pelo diretor e professor João Frade Correia, contou com um conjunto diverso de contributos de personalidades relevantes na época (Émile Planchard; José Maria Gaspar; José Lopes Dias; entre outros) de vários quadrantes: católicos, pedagógicos e patrióticos. Note-se um excerto do texto de abertura da revista: 
[...] É ainda essa alma que fulgura em Salazar; é ainda esse mesmo entusiasmo que corre nas veias do actual Subsecretário da Educação Nacional, Dr. Veiga de Macedo. É ainda ela que vibra em melodiosas ondulações na flauta rústica do pastor e aquece e faz vibrar o professor primário, que, abnegadamente, sacrificadamente, está colaborando na Campanha contra o analfabetismo e que, ao lado do pároco, constitui o grande impulso da aldeia mais sertaneja ou da vila ou cidade mais humildes. Restauram-se os templos que a alma lusíada outrora edificou; caiam-se de branco as igrejas mais pobrezinhas do nosso País, igrejas onde as almas das criancinhas penetram no luminoso campo que é o corpo místico de Cristo pelo Santo Sacramento do baptismo; igrejas onde rezamos e por nós rezam ou rezaram nossas mães e onde ainda hoje o pároco ou a professora levam os pequenitos à primeira comunhão. $\mathrm{E}$, ao mesmo tempo, desde os vergéis minhotos às floridas terras algarvias ou mesmo às nossas parcelas mais distantes, se edificam e alindam tantas escolas primárias, onde se estão a fortalecer milhares e milhares de almas pequeninas, nos mesmos ideais alevantados. $E$, à frente de cada uma, lá está um professor ou professora, de sorriso nos lábios e a mesma doçura de nossas mães no coração, a ampará-las e com elas a rezar o terço, fiadas de estrelas de estranho fulgor, que nós tantas vezes dedilhámos também com nossas mães, ainda infantes, junto à humilde lareira de nossas casas rústicas, ao rubro calor da acha de azinho. Eis todo o nosso programa. Eis o programa de todas as Escolas do Magistério do País: semear luz, espalhar amor, parcela do Amor que nos remiu (Seiva, n. 1, jan. 1955, grifos nossos).

Parece evidente a relação que se estabelece entre uma dimensão patriótica e religiosa de inspiração Cristã. Cabia ao/à professor/a do ensino primário esse desígnio de regenerar Portugal à luz do cristianismo. Estes periódicos permitiram ir ao encontro de textos produzidos por mulheres que frequentavam a Escola do Magistério Primário de Castelo Branco na década de 50 do século passado e compreender, a partir das publicações de alunas e/ou professoras, que preocupações e ideias ou ideais transmitiam nos seus textos e de que modo foram incorporando ou produzindo a sua identidade.

Neste contexto, identificamos na Página de Castelo Branco 42 textos assinados principalmente por alunas publicados entre 1953 e 1954. No caso da Seiva-Revista de Cultura a participação feminina assume uma relevância, do ponto de vista quantitativo, inferior identificando apenas, no período que decorre entre 1955 e 1959, um conjunto de seis textos assinados por mulheres, entre 21 números publicados. Provavelmente, o facto da Página de Castelo Branco ser organizada pelas alunas normalistas e, ao invés, a Seiva - Revista de cultura ter sido dirigida pelo diretor da instituição - João Frade Correia -, um católico assumido, poderá configurar uma hipótese a explorar com o objetivo de compreender a expressão dos textos assinados por elementos do sexo feminino nas duas publicações. 
A Página de Castelo Branco foi assinada exclusivamente por alunas da Escola Particular do Magistério Primário com idades compreendidas entre os 19 e os 21 anos de idade e que passamos a identificar: Maria Manuela Feijão ${ }^{1}$, Maria Luísa Ereio Delgado Robalo ${ }^{2}$, Virgínia Pacheco Ramos Palma ${ }^{3}$, Maria de Lourdes Correia ${ }^{4}$, Teresa de Jesus Ribeiro de Sousa ${ }^{5}$, Maria de Fátima Monteiro Sousa ${ }^{6}$, Maria Fernanda D. Fernandes $^{7}$, Maria de Lourdes Efigénia Dias ${ }^{8}$, Celsa Maria R. Seabra ${ }^{9}$, Filomena Purificação Patrício Silva ${ }^{10}$, Maria das Dores Cordeiro Froes ${ }^{11}$, Maria Carlota Lopes de Araújo Marques ${ }^{12}$, Maria Adelaide ${ }^{13}$, Maria da Conceição Rego de Sousa ${ }^{14}$, Maria

\footnotetext{
${ }^{1}$ Maria Manuela Feijão, natural de Vila de Rei, concelho de Vila de Rei, distrito de Castelo Branco, nasceu a 11 de junho de 1935, filha de José Feijão Júnior, realizou exame de estado em Lisboa no dia 7 de agosto de 1954 (Fonte: Arquivo da Escola Superior de Educação de Castelo Branco, Livro de exames de Estado, 1952-1975).

${ }^{2}$ Natural de Escalos de cima, concelho e distrito de Castelo Branco, nasceu a 19 de setembro de 1933, filha de Francisco Robalo, realizou exame de estado em Lisboa, no dia 7 de agosto de 1954. ${ }^{3}$ Natural de Cabeça Gorda, concelho e distrito de Beja, nasceu a 7 de dezembro de 1933, filha de José Martins Ramos Palma, realizou exame de estado em Lisboa a 7 de agosto de1954.

${ }^{4}$ Natural de Salvaterra do Extremo, concelho de Idanha a nova, distrito de Castelo Branco, nasceu a 29 de junho de 1933, filha de António Mendes Correia, realizou o exame de estado em Lisboa a 7 de agosto de 1954.

${ }^{5}$ Natural de Aguião, concelho de Arcos de Valdevez, distrito de Viana do Castelo, nasceu a 13 de junho de 1933, filha de Armindo Ribeiro de Sousa, realizou exame de estado em Coimbra a 8 de agosto de 1953.

${ }^{6}$ Natural de Nossa Senhora do Cabo, Luanda, nasceu a 19 de agosto de 1935, filha de Porfírio Monteiro de Sousa, realizou exame de estado em Coimbra a 8 de agosto de 1955.

${ }^{7}$ Natural de Sepina, concelho de Cantanhede, distrito de Coimbra, nasceu a 22 de abril de 1935, filha de Aníbal Fernandes, realizou o exame de estado em Coimbra a 8 de agosto de 1955.

${ }^{8}$ Natural de Chibia-Angola, nasceu a 21 de setembro de 1931, filha de João Rippert Mendes, realizou exame de estado em Coimbra, a 8 de agosto de 1955.

${ }^{9}$ Natural da freguesia de Sangalhos, concelho de Anadia, distrito de Aveiro, nasceu a 7 de outubro de 1934, filha de José Rodrigues Seabra, realizou o exame de estado na escola de Coimbra a 8 de agosto de 1953.

${ }^{10}$ Natural de Cernache de Bom Jardim, concelho da Sertã, distrito de Castelo branco, nasceu a 2 de fevereiro de 1936, filha de Silvino da Silva, realizou exame de estado em Coimbra, no dia 8 de agosto de 1955.

${ }^{11}$ Natural de São Pedro de Alva, concelho de Penacova, distrito de Coimbra, nasceu a 16 de julho de 1932, filha de Antero Gomes Froes, realizou exame de estado na escola de Coimbra a 8 de agosto de 1955.

${ }^{12}$ Natural da Freguesia de Pampilhosa do Botão, concelho da Mealhada no distrito de Aveiro, nasceu a 29 de janeiro de 1931, filha de Carlos Marques, realizou exame de estado em Coimbra a 8 de agosto de 1953.

${ }^{13}$ Natural de Rendufe, concelho de Tondela, distrito de Viseu, nasceu a 22 de julho de 1934, filha de Virgínia Carolina, realizou exame de estado em Coimbra a 8 de agosto de 1955.

${ }^{14}$ Natural da freguesia de Nogueira do cravo, concelho de Oliveira do Hospital no distrito de Coimbra, nasceu a 11 de julho de 1933, filha de José Joaquim de Sousa, realizou o exame de estado na escola de Coimbra a 8 de agosto de 1955.
} 
Celeste Baltazar Dias ${ }^{15}$, Marília Nair Santos Pinto Saraiva ${ }^{16}$, Maria Emília Ferreira Duarte $^{17}$, Maria de Lourdes Borrego ${ }^{18}$, Joaquina dos Santos Dias Prata ${ }^{19}$ e às professoras espanholas Maria Luz Duran ou Aurélia Guillen Acedo ${ }^{20}$. Este era o universo de alunas do magistério, ligadas maioritariamente aos distritos de Castelo Branco e/ou de Coimbra, que escreveram no periódico sobre assuntos diversos. No caso da Seiva - Revista de cultura identificamos as seguintes autoras: Maria Hermínia Romão ${ }^{21}$ e Aida Pereira Esperto ${ }^{22}$.

Tabela 1 - As grandes temáticas, escritas por alunas e/ou professoras, identificadas nos periódicos da Escola do Magistério Primário de Castelo Branco (1953-1959).

\begin{tabular}{l|ccc} 
Temáticas & $\begin{array}{c}\text { Página de Castelo Branco } \\
\text { (42) }\end{array}$ & $\begin{array}{c}\text { Seiva - Revista de } \\
\text { Cultura (6) }\end{array}$ & Total (48) \\
\hline Profissão/Escola & 6 & 3 & 9 \\
Religião/Moral & 5 & 1 & 6 \\
Ideal de Mulher & 6 & 1 & 7 \\
Criatividade/Poesia & 17 & - & 17 \\
Outros/diversos & 8 & 1 & 9
\end{tabular}

Fonte: Autores (2019).

As principais temáticas que foram publicadas podem arrumar-se nas seguintes categorias referidas na Tabela 1 . A categoria com maior expressão quantitativa (17

\footnotetext{
${ }^{15}$ Natural da freguesia da Sé Nova, concelho e distrito de Coimbra, nasceu a 13 de janeiro de 1935, filha de António Dias de Oliveira, realizou exame de estado em Coimbra no dia 8 de agosto de 1955.

${ }^{16}$ Natural de Midões, concelho de Tábua, distrito de Coimbra, nasceu a 27 de maio de 1934, filha de Ernesto dos Santos Saraiva e realizou o exame de estado em Coimbra no dia 8 de agosto de 1953.

${ }^{17}$ Natural de riachos, concelho de Torres Novas, distrito de Santarém, nasceu a 10 de julho de 1933, filha de Manuel Antunes Duarte, realizou exame de estado em Coimbra a 8 de agosto de 1953.

${ }^{18}$ Natural de carvalhal, concelho da sertã, distrito de castelo branco, nasceu a 6 de julho de 1936, filha de César Augusto Mota saraiva, realizou exame de estado em Coimbra a 8 de agosto de 1955.

${ }^{19}$ Natural de Atalaia do Campo, concelho do Fundão, distrito de Castelo Branco, nasceu a 13 de agosto de 1934, filha de José Dias Rato, realizou exame de estado em Lisboa no dia 7 de agosto de 1954.

20 Pertencia à Escola do Magistério de Cáceres (Espanha) (Fonte: Arquivo da Escola Superior de Educação de Castelo Branco, Livro de exames de Estado, 1952-1975).

${ }^{21}$ Natural da freguesia de São Bartolomeu, concelho de Vila Viçosa, distrito de Évora, nasceu a 23 de março de 1935, filha de Alberto Antunes Valente Esteves, realizou exame de estado em Coimbra a 26 de julho de 1956.

22 Natural do Sardoal, distrito de Santarém, nasceu a 1 de maio de 1937, filha de José Oliveira Esperto, realizou exame de estado em Coimbra a 26 de julho de 1956.
} 
textos) é a que diz respeito a publicações relacionadas com poesias, textos dramáticos e/ou criativos e pequenas histórias moralizadoras. A título de exemplo recuperamos um poema de uma das alunas da instituição:

\footnotetext{
"Quem nos dá o pão do saber,

Quem nos ensina a vencer,

Dificuldades da vida?

Quem nos guia para o Bem,

Quem é que nos faz Alguém

Neste mundo de vingança?

A Escola, facho ardente,

Que encaminha docemente,

D'olhos postos num ideal

E p'ra um melhor Portugal,

Os passitos da criança.

(Saraiva, Poesia, 15/04/1954)
}

Este poema, da autoria de Marília Nair Santos Saraiva, aborda a importância da instituição escolar na vida das crianças e a sua relevância na construção de uma moral cristã e nacionalista.

A segunda categoria - profissão/escola - que identificamos com maior número de textos publicados (9) diz respeito a assuntos relacionados diretamente com a missão atribuída ao professor naquele tempo. A este propósito Celsa Moreira Rodrigues Seabra, diplomada pela Escola Particular do Magistério Primário de Castelo Branco, faz a comparação do exercício da docência com a atividade do pároco pois "a professora e o pároco têm uma grande seara na sua frente! Tantas almas esperando em alvoroço a sementeira da palavra e do exemplo" (Página de Castelo Branco, 1954). Nesta categoria incluímos também textos relacionados com aspetos de natureza pedagógica ou relacionados com o papel da família na educação das crianças.

$\mathrm{Na}$ terceira categoria - ideal de mulher - identificamos um conjunto de textos (7) relacionados com o lugar que a mulher ocupava ou deveria ocupar na sociedade. Seguido de perto, a quarta categoria - religião/moral - remete-nos para discursos de natureza axiológica (6) de inspiração cristã definidores de uma determinada forma de 
moldar a sociedade e a própria formação dos/as futuros/as professores/as. Além destas categorias surgiram outros textos (9), com temáticas muitos diversificadas, que consideramos na categoria - outros/diversos.

O conjunto de categorias identificadas permitiram evidenciar duas configurações identitárias a partir dos discursos relacionados com as autoras que os produziram. Na verdade, parece estarmos perante uma identidade atribuída e, por outro lado, um processo identitário adaptado. É em torno destas duas configurações identitárias que procuraremos colocar em evidência a voz das mulheres naquele contexto específico de formação.

\section{Discursos de inspiração católica no feminino: uma identidade atribuída}

Os textos que suportaram a nossa análise (48) permitem reforçar a ideia do discurso enquanto objeto, palco de lutas e tensões ou de poder. Os discursos, como refere Chartier (2002, p. 17), constituem-se como “atores” que produzem estratégias e práticas (sociais, escolares, políticas) que tendem a impor uma autoridade à custa de outros, por el[e] menosprezados, a legitimar um projeto reformador ou a justificar, para os próprios indivíduos, as suas escolhas e condutas. Na verdade, a análise de discursos ou teias discursivas implicam afrontamentos entre instituições, perspectivas ideológicas ou entre homens e mulheres.

Tomando o discurso como objeto de estudo tornou-se evidente, a partir do corpus documental definido, que os discursos produzidos pelas autoras contribuem, na sua globalidade, para aquilo que podemos designar de uma identidade atribuida. Os discursos analisados traduzem, em grande parte, aquilo que é o lugar reservado à mulher na sociedade portuguesa daquele tempo. Entendemos que a identidade atribuida, em linha com o pensamento de Dubar (1997), prende-se com mecanismos diversos que visam mostrar ao indivíduo "que tipo de homem (ou de mulher) você é [ou deve ser]" (p. 106).

Este processo de etiquetagem funciona no interior de um sistema de ação que pode ser enquadrado por diferentes entidades, entre elas o Estado ou a Igreja, de onde emergem relações de poder que permitem produzir um determinado tipo de 
comportamento, hábito, atitude ou forma de pensar ancorados a determinados grupos socioprofissionais. É o caso dos indivíduos que pretendiam tornar-se professores/as. Para alcançar o exercício desta atividade na década de 50 todos/as deveriam passar por uma instituição de formação onde incorporavam, além de conhecimentos específicos, um conjunto de "valores, normas e disposições" que permitiam a sua identificação (ou incorporação identitária) com o grupo profissional dos/as professores/as, conquistando legitimidade social através da sua formação (nomeadamente, dos conhecimentos que possuíam e dos valores que representavam).

A configuração identitária associada ao universo feminino na década de 50, do século XX, que designamos de identidade atribuida, assume, em si mesma, um conjunto de três dimensões que permitem a sua estruturação conceptual: a dimensão sociomoral; a dimensão patriótica; e, a dimensão profissional. Todas estas dimensões encontram-se relacionadas e contribuem para a construção de uma identidade atribuida.

A dimensão sociomoral pode definir-se como um sistema de valores que legitimam a ação do indivíduo num determinado quadro social e político. Esta dimensão encontra espaço no interior dos quotidianos formativos dos/as grupos profissionais relevantes ao "regular" funcionamento da sociedade, de que era exemplo o caso dos/as futuros/as professores/as. Marília Nair Saraiva (1955, p. 31) exemplifica quando refere:

[...] Há uma ciência que por vezes se esquece e que é sem dúvida a mais necessária e a maior auxiliar da mulher em geral: a formação moral. A mulher culta, sem formação religiosa, é absolutamente incapaz de defender devidamente os seus interesses mais altos em intima união com a sua honra e dignidade. [...] A mulher deve, sem dúvida, ser instruída, por poderá junto com o homem completar uma obra grande e prestar relevantes serviços à família e sociedade, mas ela não poderá nunca esquecer que é acima de tudo uma criatura de Deus.

No decorrer da análise realizada, é comum encontrar referências aos valores de inspiração Cristã (Católicos) no âmbito da formação das futuras professoras, dado que a Igreja assumiu um importante papel no contexto do regime político então vigente em Portugal: o Estado Novo. Deste modo, verifica-se que são realçados os valores da bondade, do amor, da dedicação, do sacrifício, enquanto elementos estruturantes daquela época no discurso das autoras que contribuíram para os 
periódicos analisados. Virgínia Ramos Palma (1953) assume a inspiração nestes princípios quando afirma:

[...] se a nossa vida for feita de Amor e Ideal, se a nossa profissão for exercida com alma e dedicação. Esse amor levá-lo-emos nos lábios e no coração, esse Ideal iluminará a estrada que nos conduzirá ao Bem Supremo e por onde encaminharemos as almas, ainda tão tenras, dos nossos alunos [...] (Página de Castelo Branco, n. 1).

De igual modo, são vários os textos que invocam o "Divino" para justificar as suas ações ou opções pessoais e/ou profissionais. Maria (1954), a este propósito, é perentória quanto à manifestação divina no êxito que procura encontrar na sua atividade profissional de professora:

[...] Valeu-me muito, muito a coragem que Nossa Senhora depositou na minha alma, no dia da nossa festazinha de Consagração! E quanto Nossa Senhora é minha amiga! É nossa amiga! Hoje já estou resignada; estou feliz. Quantas vezes ouvi nessa nossa Escola o nosso Diretor, aos nossos professores e, depois, ao Sr. D. Agostinho de Moura, que é preciso trazermos a nossa alma incendiada por nobres ideais! Quantas vezes! [...] [Às crianças] Não me esqueço, não...de lhes incutir bem nas suas almas delicadas o amor por Jesus. Penso fazer com eles uma pequenita festa dedicada à primeira comunhão de muitas dessas crianças. Com muitas rezo o terço na escola, antes de sair e pedimos que Deus nos proteja, proteja os pobres pais que trabalham no campo, dia inteiro, e ainda pelos seus doentes e pelos parentes que andam lá por longe! (Página de Castelo Branco, n. 3).

O enquadramento axiológico não podia ser mais claro. Há uma âncora evidente entre os princípios apropriados no seu quotidiano formativo, incutidos pelo diretor, professores da instituição e autoridades religiosas (nomeadamente o Bispo da diocese de Portalegre-Castelo Branco), e a sua prática profissional. Parece haver uma preocupação maior com as questões morais face aos aspetos de natureza pedagógica e científica que nem sequer são referidos no excerto anterior. A dimensão sociomoral constitui, em nosso entender, o verdadeiro enquadramento da profissão de professor naquele tempo e sobretudo, ainda com maior destaque, do universo feminino que compõe esta atividade no regime político do Estado Novo, a quem era atribuída essa missão de espalhar os princípios sociomorais junto das crianças (e dos seus pais) como mecanismo de garantia de sustentabilidade de um regime político próximo da Igreja Católica.

Precisas de auxiliar, ler e recomendar a imprensa católica. As alunas das Escolas do Magistério, amanhã professoras, têm de fazer parte do fermento que está renovando e 
alimentado a nova vida em Portugal. Deves ser, rapariga católica, noiva católica, e, amanhã, ao constituir um lar, esse lar deve ser impregnado de espirito cristão. Só um lar assim pode fazer a tua felicidade, a de toda a tua família. (Página de Castelo Branco, n. 4,1954$)$.

$\mathrm{Na}$ verdade, a tarefa que cabia às mulheres professoras constituía um prolongamento daquilo que deveriam fazer em sua casa (privado) para o domínio público. É neste sentido que, em fevereiro de 1954, é publicado um texto na Página de Castelo Branco, dirigido às alunas normalistas, onde se pode ler:

\footnotetext{
Prepara a tua alma para receberes com elevação os ensinamentos dos teus Mestres. lluminando-a, para que amanhã possas aquecer e orientar as pequeninas almas que esperam por ti. As criancinhas não esperam erudição da nossa parte, mas esclarecimento. Se o teu coração for puro, será pura e doce a tua palavra e elevadas as tuas ideias. As tuas palavras serão a fonte onde as pequeninas irão beber a consolação das tuas amarguras. $\mathbf{O}$ teu lar deve ser a tua Escola. E, se casares, a tua Escola deve ainda continuar a ser o prolongamento do teu lar. (Página de Castelo Branco, n. 4, grifos nossos)
}

Como decorre da leitura do excerto anterior, as "ideias" ou conhecimento cientifico-pedagógico apenas podiam desenvolver-se se existissem condições morais apropriadas. Por isso, o investimento deveria ser primeiramente moral e só posteriormente de natureza científica ou pedagógica.

A dimensão sociomoral, que procuramos caraterizar anteriormente, concorre de modo inequívoco para a circulação de ideais nacionalistas e patrióticos. Estamos perante um regime político que soube usar habilmente a moral cristã a seu favor e que a colocou a circular com grande centralidade no interior das escolas. Este aspeto transporta-nos para a segunda dimensão identificada - a dimensão patriótica - que compõe aquilo que entendemos ser uma identidade atribuída.

Como já afirmamos anteriormente, estas dimensões não constituem mecanismos autónomos ou singulares, pelo contrário funcionam como um todo que permite atingir o indivíduo no coração (VEYNE, 1988). A visão do universo feminino que encontramos em alguns textos analisados nos periódicos apresenta a Escola como uma "oficina de almas" onde o discurso sobre a Pátria deveria ter lugar de relevo. É bem esclarecedor um excerto do texto que Virgínia Ramos Palma (1953) escreve quando afirma o papel da mulher-professora: "Formaremos assim, não apenas homens e mulheres, mas portugueses de valor que constituirão uma geração que há-de 
servir de base à continuidade da nossa Pátria" (Página de Castelo Branco, n. 1). Este excerto é exemplar do contributo que a dimensão moral assume no contexto da produção de "bons portugueses". A mulher-professora assume esse desígnio de valorização da Pátria. É elucidativo o argumento utilizado quando afirma que: "Portugal, o Portugal de amanhã, está nas nossas mãos, raparigas, nas nossas mãos que serão as que, amanhã, arranjarão o lar, que acariciarão os filhos, mães de futuras mães e, portanto, de futuras educadoras" (PALMA, 1954).

A Pátria constitui esse elemento presente no âmbito dos discursos femininos identificados. Este tipo de discursos, de cariz nacionalista, representa o caminho definido por António de Oliveira Salazar para algumas das mulheres portuguesas. A mulher enquanto esteio da moral e da pátria.

Entramos agora na terceira dimensão que é enquadrada pelas anteriores: a dimensão profissional. As autoras que escrevem nos periódicos analisados parecem limitar-se a reproduzir aquilo que a sociedade esperava delas. Por um lado, escrevem e enquadram o seu discurso do ponto de vista moral e por outro valorizam a pátria junto das suas crianças, ou daquelas que podem vir a ser as suas crianças, no seio da profissão que, aparentemente, desejavam exercer.

Apesar de reconhecermos que a análise realizada produziu resultados que permitem afirmar a construção de uma identidade enquadrada pela moral cristã e pelo espirito nacionalista, constituindo-se a profissão como um sacerdócio, não deixa de ser importante verificar que algumas das mulheres que escreveram também tinham preocupações de natureza pedagógica que se materializaram em discursos sobre a relação da Escola com a Família. A este propósito Virgínia Ramos Palma (1954) afirma:

A obra educativa foi e será essencialmente da Família, por ser com esta que a criança priva desde o berço e com ela inicia toda a sua actividade social. Associada à família e com ela estritamente relacionada está a Escola, para onde a criança é atirada e onde vai encontrar um meio que, embora completamente diferente do lar, servirá de continuação à vida iniciada no seio da família. Antigamente a aç̧ão da Escola era quase exclusivamente instrutiva, porque a família preenchia, capazmente e sozinha toda a tarefa educativa. E conseguia-o porque assentava em bases sólidas, em princípios sãos e essencialmente cristãos (Página de Castelo Branco, n. 4). 
Como é percetível são preocupações pedagógicas que assumem, de acordo com a retórica da época, a família como instância primeira da educação das crianças. Todavia é realçado o papel da Escola neste processo. Aliás, a autora preocupa-se essencialmente com a transição da criança entre a Família e a Escola e, de algum modo, coloca em causa os valores da própria família onde, caso não assentassem em princípios sólidos, “essencialmente Cristãos”, a tarefa educativa da Escola tornava-se mais profunda no processo que lhe competia quer de instrução, quer de moralização. Assim, para Virgínia Ramos Palma (1954):

\begin{abstract}
A tarefa do professor é, portanto, embora na essência concorra para o mesmo fim, diferente da família. Da família a criança recebe, completamente novas, as impressões, os exemplos dos seres que a rodeiam. Na escola a criança não as recebe, modifica-as. Está nisto a modificação de hábitos maus, a sublimação de tendências, a abdicação completa de certos hábitos para seguir outros completamente diferentes, etc.... Além disso o professor, ao tentar atingir o ideal educativo, luta contra uma série de forças, forças contraditórias e que por vezes tendem a não concorrer para o fim desejado.
\end{abstract}

Efetivamente, a Escola devia assumir o poder de transformação do indivíduo. Não obstante, essa transformação constitui, em concreto, um processo de regulação do comportamento da criança. Daí que se escreva sobre a necessidade de "modificação de hábitos maus", realçando o papel do professor que deve contrariar forças que não concorrem para o mesmo objetivo, emergentes muitas vezes na própria família. Palma (1954) é perentória quando diz que os "valores morais estão a ser cada vez mais desprezados e, por isso, cada vez pesa mais sobre a escola a responsabilidade tremenda de educar, mas educar convenientemente a família em todos os seus encargos, não só morais, como também materiais" (Página de Castelo Branco, $\mathrm{n}^{\circ}$ 4). A Escola, e, portanto, o/a professor/a, assumem este desígnio de educar convenientemente não apenas as crianças, mas também as famílias, procurando incutir-lhes os valores apropriados.

Este conjunto de três dimensões - sociomoral; patriótica e profissional concorrem para a representação da aluna normalista/ mulher professora como um sujeito que corresponde, em grande medida, aquilo que se esperava que fosse a sua ação naquele contexto. De um lado, a valorização de uma moral Cristã; do outro lado, a exaltação da Pátria. Ancorado a tudo isto surgem discursos que concorrem essencialmente para a construção de uma atividade profissional onde existem 
preocupações com o papel do/a professor/a, da Escola ou com as questões pedagógicas relacionadas com a família. Embora estejamos a falar, essencialmente, de um contexto de formação de professoras influenciado fortemente pela moral e pela pátria não é de somenos importante relevar as preocupações pedagógicas que se prendem com a valorização de um saber profissional e relacional em construção.

\section{Discursos de inspiração católica no feminino: uma identidade adaptada}

Embora estejamos no interior de um sistema de ação bem definido pelo regime político do Estado Novo e pela própria Igreja Católica não é de menosprezar algumas evidências que concorrem para a construção daquilo que procuramos designar de uma identidade adaptada. Ao longo da análise realizada aos discursos identificados fomos percebendo que em determinados textos se verifica a existência de alguns "desvios" discursivos da etiquetagem "atribuída" à mulher, embora devidamente enquadrados na lógica que imperava. Efetivamente, se por um lado se afirma que a professora deve dedicar-se "com espirito de sacrifício, sem quaisquer ressentimentos, ao sacerdócio da sua profissão" (PALMA, 1954); por outro lado, também encontramos evidências que prenunciam a afirmação da mulher - ainda que enquadrada pelas dimensões moral e patriótica. Parece haver, em certos casos bastante dissimulados, um conjunto de argumentos que vão surgindo exaltando, por exemplo, a figura da própria mulher. Argumentos inspirados no quadro de ação em que se movimenta vai-se afirmando que "a mulher tem de ser Mulher, e acima de tudo, Portuguesa. Tem de ter aquele cunho tão pessoal que a torne notada e admirada em toda a parte” (PALMA, 1953). Por isso:

Hoje, mais do que nunca, é grande a responsabilidade da Mulher, é enorme a responsabilidade da Mulher Portuguesa. E digo grande, enorme, porque melhor se reconhece a grandeza no meio da mediocridade. [...] E se em todas as épocas foi sempre a mulher a chama do espirito, quem soube mantar e continuar os valores espirituais, agora, mais do que nunca, ela tem de os levantar, tem de erguer ao prestigio perdido as nossas tão belas tradições, o nosso tão reconhecido mérito, todo o nosso património espiritual. Mas a luta que nos propomos começar de alguém tem de partir e nós queremos, raparigas portuguesas, raparigas cristãs, normalistas, que parta de nós, queremos ser a nascente dum rio caudaloso que há-de inundar fertilmente os terrenos 
onde serão implantadas, por nós, as sementes de todas as virtudes aviltadas e perdidas (PALMA, n. 1, 1953).

Essa tarefa da mulher pode significar um mecanismo encontrado para se assumir numa sociedade fechada, patriarcal e num regime político que não oferecia muitas possibilidades de participação na vida pública ou de mobilidade social para as mulheres. Neste sentido, Maria Hermínia Romão (1955, p. 30) utiliza habilmente os exemplos do Cristianismo para mostrar a possibilidade de emancipação da mulher:

O Cristianismo deu-nos figuras femininas exemplares e admiráveis! Quem esquecerá jamais as figuras notabilíssimas de Catarina de Sena, Joana D'Arc e, dentro de Portugal, Filipa de Vilhena e a nossa gloriosa rainha Santa Isabel? Mas como poderia este facto ser doutra maneira, se na religião cristã parte duma mulher a causa do Mistério da redenção? Porém, isto, esquece-o a falsa ciência, quando gritando bem alto chama a mulher à libertação e emancipação, pretendendo submete-la à moral materialista, a única que aprisiona e atrofia todas as faculdades humanas, rebaixando-nos à miséria e decadência da sociedade dos nossos dias.

Estes argumentos mostram que embora a mulher, a aluna, a professora correspondessem a uma identidade atribuída/incorporada não esquecia a importância de se afirmar na medida das possibilidades da época. É curioso o excerto que apresentamos a seguir onde se pode ler:

Estamos em frente duma vida nova, mas que é preciso saber viver. Não sejamos daquelas que cruzam os braços e quedam ante as dificuldades. Educadoras do século XX temos o dever de ser revolucionárias, mas revolucionárias no bom sentido. [...] Sejamos, pois, verdadeiras Apóstolas de Cristo" (SARAIVA, 1954).

Esta afirmação indicia uma consciência própria sobre o papel que a aluna normalista/mulher/ professora poderiam assumir naquele tempo. Representa, em nosso entender, uma estratégia de afirmação do universo feminino que soube integrar-se nos desígnios que lhe eram atribuídos e aproveitá-los, de modo a afirmar a sua condição socioprofissional e de género.

\section{Considerações finais}

Neste texto procuramos interpretar os discursos que as alunas normalistas e/ou professoras da Escola do Magistério Primário de Castelo Branco produziram 
para dois periódicos da instituição, tomando em consideração o contexto em que escreveram, o regime político e a própria condição da mulher na sociedade portuguesa da década de 50 do século XX.

Percebemos que há um conjunto de normas e valores, próprios da moral cristã e do nacionalismo da época, que são replicados no conjunto dos discursos produzidos pelas autoras. Como afirmamos anteriormente, parece desenvolver-se uma identidade atribuída ao género feminino a que deviam corresponder no seu quotidiano formativo e, posteriormente, no exercício do seu magistério. O lugar da mulher no regime político do Estado Novo estava muito bem definido. Na verdade, a Escola do Magistério Primário de Castelo Branco parece constituir-se como um "microcosmo" que reflete o "macrocosmos" do universo total (BERGER; LUCKMANN, 2004, p. 99).

Todavia, apesar da forte pressão do enquadramento institucional, político e social no processo de formação daquelas mulheres não deixamos de evidenciar também a sua capacidade de adaptação aquele estreito caminho que podiam percorrer com o objetivo de fortalecer a sua própria condição. Aquilo a que chamamos de uma identidade adaptada. Adaptada às circunstâncias políticas e sociais da época onde as alunas e/ou professoras foram capazes de encontrar algumas estratégias de afirmação transformando as dificuldades sociomorais em oportunidades de reforçar uma visão, ainda que adaptada, sobre o seu papel em termos sociais e educativos.

Em suma, se é verdade que a análise realizada sobre os discursos das mulheres nos periódicos da Escola Particular do Magistério Primário de Castelo Branco revelou a existência de uma identidade atribuída resultante de um sistema de valores e princípios inspirados na moral cristã e na valorização da Pátria Portuguesa. Também, é curioso perceber que apesar deste sistema de ação relativamente fechado, a mulher foi encontrando formas de evidenciar a sua importância na sociedade portuguesa. Efetivamente, estamos perante uma estratégia identitária que implica a incorporação dos princípios da época, mas não esquece, como afirma Dubar (1997, p. 107), “o desejo de construir para si novas identidades no futuro". 


\section{Referências}

ARAÚJO, H. As mulheres professoras e o Ensino Estatal. Revista Critica de Ciência Sociais, n. 29, p. 81-103, fev. 1990.

BERGER, P.; LUCKMANN, T. A construção social da realidade: um livro sobre a sociologia do conhecimento. 2. ed. Lisboa: Dinalivro, 2004.

CATANI, D.; SOUSA, C. Imprensa periódica educacional paulista (1890-1996). Catálogo. São Paulo, 1999.

CHARTIER, R. A História cultural - entre práticas e representações. Lisboa: Difel, 2002.

CORREIA, J. F. A Missão do professor. Página de Castelo Branco, n. 9, abr. 1954.

DUBAR, C. A Socializ̧ação: Construção das identidades Sociais e Profissionais. Porto: Porto Editora, 1997.

ESCOBAR, L. O Sexo das Profissões: Género e Identidade Socioprofissional em Enfermagem. Porto: Ed. Afrontamento, 2004.

FERREIRA, Ó. R. História da Escola Técnica de Enfermeiras (1940-1968). Lisboa: Instituto de Educação, Universidade de Lisboa, 2012.

FERRO, A. Salazar. O Homem e a Obra. Lisboa: Empresa Nacional de Publicidade, 1933.

FISCHER, R. Foucault e a análise do discurso em educação. Cadernos de Pesquisa, n. 114, p. 197-223, nov. 2001.

HENRIQUES, H.; ORLANDO, E. A pedagogia do catecismo na Escola Normal Particular Amato Lusitano através da "Seiva - Revista de Cultura" (1955-1959). In: HERNANDEZ DIAZ, J. M. (Eds.). La prensa de los Escolares y Estudiantes: Su contribuición al património histórico educativo. Salamanca: Ediciones Universidad de Salamca, 2015. p. 451-464.

HENRIQUES, H. Formar professores: a Escola Normal Particular Amato Lusitano (1950-1973). Revista de Estudios Humanisticos: Historia, n. 10, p. 229-244, 2011.

HENRIQUES, H. Escolas de Formação de Professores em Castelo Branco (1898 - 1988) In: PINTASSILGO. J. (Coord.). Escolas de Formação de Professores em Portugal. Lisboa: Colibri, 2012. pp. 119-148.

HENRIQUES, H. M. G. Formação, Sociedade e Identidade Profissional dos Enfermeiros: A Escola de Enfermagem de Castelo Branco/Dr. Lopes Dias (1948-1988). Tese (Doutorado em Ciências da Educação) — Universidade de Coimbra, Coimbra, 2011. 
HERNANDEZ DIAZ, J. M. Prensa pedagógica en Castilla y León. Repertório Analitico (1793-1936). Salamanca: Hergar Ediciones Antema, 2015.

NÓVOA, A. Le Temps des Professeurs: Analyse socio-historique de la profession enseignante au Portugal (XVIII'-XXe siécle). Lisboa: INIC, 1987.

NÓVOA, A. A Educação Nacional. In: ROSAS, F. (coord.). Nova História de Portugal: Portugal e o Estado Novo 1930-1960, Vol. XII, Lisboa: Editorial Presença, 1992.

NÓVOA, A. A Imprensa de Educação e Ensino: Repertório Analítico (Séculos XIX-XX). Lisboa: Instituto de Inovação Educacional, 1993.

NÓVOA, A. Profissão Professor. 2. ed., Porto: Porto Editora, 1995.

PIMENTEL, I. F. História das Organizações Femininas no Estado Novo. Lisboa: Temas e Debates, 2001.

PINTO, J. M. (1991). Considerações Sobre a Produção Social de Identidade. Revista Critica de Ciências Sociais, Coimbra: Centro de Estudos Sociais, pp. 217 - 231.

TAVARES, D. Escola e Identidade Profissional: o caso dos Técnicos de Cardiopneumologia. Lisboa: Colibri, 2007.

VEYNE, P. O Indivíduo atingido no coração pelo poder público. In: VERNANT, J. P.; VEYNE, P.; RICOEUR, P. Indivíduo e Poder. Lisboa: Edições 70, 1988.

\section{Fontes}

Arquivo da Escola Superior de Educação do Instituto Politécnico de Castelo Branco - Livros de Exames de Estado da Escola do Magistério Primário de Castelo Branco (1955-1973).

CORreiA, M. L. A Minha escola. Página de Castelo Branco, n. 5, fev. 1954.

ESPERTO, A. P. É este o teu caminho. Seiva - revista de cultura, ano II, n. 5, p. 167-171, mar./abr. 1956.

FERREIRA, M. E. A mulher. Página de Castelo Branco, n. 9, abr. 1954.

FROES, M. D. C. Uma vida nova. Página de Castelo Branco, n. 6, mar. 1954.

LOURDES, M. Carta a minha mãe. Página de Castelo Branco, n. 1, dez. 1953.

LUÍSA, M. Primeiras palavras. Página de Castelo Branco, n. 1, dez. 1953.

MARIA. Cartas da Serra. Página de Castelo Branco, n. 3, jan. 1954.

PÁGINA DE CASTELO BRANCO. Colega. n. 4, fev. 1954.

PALMA, V. R. A Escola e a Família. Página de Castelo Branco, n. 4, fev. 1954. 
PALMA, V. R. Divagando. Página de Castelo Branco, n. 6, mar. 1954.

PALMA, V. R. Mulher Portuguesa. Página de Castelo Branco, n. 1, dez. 1953.

ROMÃO, M. H. A família e a Sociedade. Seiva - revista de cultura, ano II, n. 2, p. 51-53, nov. 1955.

ROMÃO, M. H. A mulher dos nossos tempos. Seiva - revista de cultura, ano I, n. 2, p. 30-33, fev. 1955.

SARAIVA, M. N. S. P. Vida nova. Página de Castelo Branco, n. 13, jul. 1954.

SARAIVA, M. N. S. Poesia. Página de Castelo Branco, n. 9, abr. 1954.

SEABRA, C. M. R. Primeiro ano de professora. Página de Castelo Branco, n. 4, fev. 1954.

SOUSA, M. F. M. Essa Luz.... Página de Castelo Branco, n. 4, fev. 1954.

SOUSA, T. R. A nossa escola. Página de Castelo Branco, n. 10, mai. 1954.

RECEBIDO: 04/03/2019

RECEIVED: 03/04/2019

RECIBIDO: 04/03/2019

APROVADO: 30/10/2019

APPROVED: $10 / 30 / 2019$

APROBADO: 30/10/2019 